\section{Action now - no more talk!}

\author{
Anne-Marie Levy \\ Head of Research Policy \\ The Science FacultyUniversity of Copenhagen, Øster Voldgade 3, \\ 1350 Copenhagen, Denmark
}

Cientific and technological development is fundamental for a competitive knowledge society. General and specialised scientific or technological knowledge is increasingly called upon in professional and daily life, in public debates, decision making and legislation. All citizens need a basic understanding of mathematics, science (hereon defined as natural science, ie. physics) and technology. If Europe is to maintain, let alone to improve, its position in the world, and to meet the Lisbon targets, we need a strategic research and education policy.

The globalization of the economy includes both opportunities and challenges for R\&D based companies. And globalisation is already happening! All R\&D based companies are globally oriented. Clear evidence of globalization can be found if one looks at the share of global GDP growth from 1995 to 2002. Asia, excluding Japan alone, had a share of $43 \%$, USA $20 \%$, EU $14 \%$, Japan $2 \%$ and ROW $21 \%$. This presents a challenge for the European companies.

\section{The goal for Europe}

"The Union has today set itself a new strategic goal for the next decade: to become the most competitive and dynamic economy in the world capable of sustainable economic growth with more and better jobs and greater social cohesion." Presidency conclusions, Lisbon European Council, 23-24 March, 2000.

This was the goal set out by the European Commission in March 2000. The science community is a central player in achieving that goal to become the most knowledge-based economy and society in the world.

But how are we doing in Europe? Are we moving towards the goals?

If we look at how old Europe is doing in a larger perspective, there is a need for structural changes in tax, labour market, agriculture and immigration. If one looks at the European electorate, we see the contours of the growing demographic challenges ahead. One in five is retired, one in five is on public support, one in four is employed by public sector and $35 \%$ is employed by private sector. The demographic outlook tells us than there are going to be fewer hands to support an increasingly ageing population. In Europe we are also weak in high-tech value-added products. The high-tech share of total exports in Denmark is $14 \%$ (EU average $21 \%$ ), whereas in the USA it is $28 \%$ and in Japan $25 \%$.

How do we compare in other respects with competing parts of the world. If one looks at Asia, which has $50 \%$ of world population, there is a young population, with a desire to succeed and a strong personal drive among individuals. In the USA, there is a more happy marriage between technology, money, individual drive and aspiration than in Europe and where immigrants are seen overall as an asset.

\section{Business R\&D and the link to universities}

Business R\&D and innovation are linked to economic growth and productivity gains. Competition is growing and many countries aim to increase innovative capabilities (see table 1). To support this, the national authorities must make room for public investment as well as improved framework conditions for private R\&D and innovation spending.

$\nabla$ Table 1: The level of R\&D investments

\begin{tabular}{llll}
\hline Country/region & R\&D intensity & R\&D target & Target date \\
Austria & $1.88 \%$ & $2.5 \%$ of GDP & 2005 \\
Canada & $1.93 \%$ & Top 5 in OECD & 2010 \\
EU & $1.88 \%$ & $3.0 \%$ & 2010 \\
Germany & $2.53 \%$ & $3.0 \%$ & 2010 \\
Hungary & $0.81 \%$ & OECD avg. & 2006 \\
Korea & $2.68 \%$ & $5 \%$ of gov't spend & 2002 \\
Norway & $1.46 \%$ & OECD avg. & 2005 \\
Spain & $0.96 \%$ & $1.29 \%$ of GDP & 2003 \\
\hline
\end{tabular}

Source: OECD

There are good reasons to encourage industry-science partnerships. The formal partnerships through joint laboratories, spin-offs and licensing are well known. But also the informal partnerships through mobility of researchers, co-publications \& conferences, flow of graduates to industry, and research contracts are all a part of the increasing vital co-operation between universities and industry.

The routes to commercialisation of basic research can be pursued through three different paths. The entrepreneurial route with spin-offs/spin-outs, the patenting route through licensing of technology and the co-operative route through joint and collaborative research.

However the essential condition to obtain the European goal of becoming the most competitive and dynamic knowledge-based economy in the world is that we have the right number of human resources in science, engineering and technology. It is here that the EU member states have a challenge in the coming years.

\section{Shortage of science skills}

The EU states have called for an increase in the proportion of European GDP invested in research from $1.9 \%$ to $3 \%$. This is called the Barcelona goal. In terms of human resources, it is estimated that an extra 0.5 million researchers (or 1.2 million research-related personnel) are needed to meet that goal between now and 2010 in addition to the current number of researchers (see table 2 and figure 1). This is on top of the required replacement of the ageing workforce in research.

$\checkmark$ Table 2: Number of graduates in Mathematics, Science and Technology and Number of Researchers and Engineers.

\begin{tabular}{ccc}
\hline Region & Graduates (2000) & Researchers and Engineers (1999) \\
EU (15) & 555647 & 919796 \\
USA & 369391 & 1219407 \\
Japan & 236670 & 658910 \\
\hline
\end{tabular}

Source: RTD, Third European Report on S\&T Indicators

Data Source: Eurostate Education Statistics

Note: The number of graduates does not include data for Greece (not available); The number includes graduates in science, mathematics, computing and engineering.

The question is thus: Will Europe experience a serious shortage of science-related personnel and a serious lack of skills in science over the next 10 years? 
The trends in the choice of education of the younger generations does not support the need for more qualified researchers in science. On the contrary, it justifies why action is needed now. We know that the numbers of students who choose to study science has been decreasing over the last decade. Also the (negative) change of attitude of students towards science is a big problem.

On the other hand, the requirements of the European economy for more science-trained personnel is rapidly increasing.

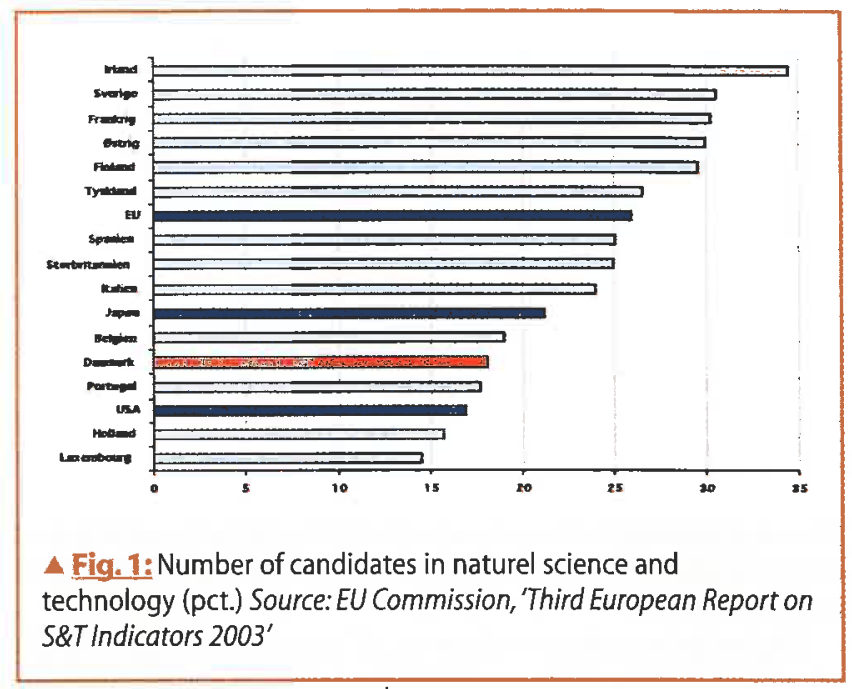

\section{Science for all}

There is a need not only to continue to encourage children and young people to take a greater interest in science and mathematics but also to ensure that those already in scientific and research careers find their careers, prospects and rewards sufficiently satisfactory to keep them there. In this context, gender balance must be encouraged.

We must also continue to underline the importance of increasing recruitment to scientific and technological disciplines, including a general renewal of pedagogy and closer links to working life and industry throughout the whole educational and training system. This will contribute to the construction of the European research area.

$\checkmark$ Table 3: Estimates of percentages of student who no longer consider a career in science to be a personal prospect at different stages of the educational system.

\begin{tabular}{ccc}
\hline Age & $\begin{array}{c}\text { Percentage Stating Research in } \\
\text { MST is not a Career Option }\end{array}$ & $\begin{array}{c}\text { Decrease in interest as } \\
\text { compared to input at that level }\end{array}$ \\
9 & $20 \%$ & $20 \%$ \\
12 & $50 \%$ & $37.5 \%$ \\
16 & $75 \%$ & $50 \%$ \\
18 & $90 \%$ & $60 \%$ \\
22 & $95 \%$ & $50 \%$ \\
26 & $98 \%$ & $60 \%$ \\
\hline
\end{tabular}

Up to the age of 18, the percentages considering careers in science and research-related careers are indistinguishable at this level of accuracy. The Table is a compilation from numerous studies on student interest in and attitudes towards science. In this table science is defined as the systematic study of the nature and behaviour of the material and physical universe, together with mathematics, the social and economic sciences and some branches of the humanities.

Source: The European Commission
But the food chain to a career in scientific research is weak. When one examines table 3, it shows that students leak out of the pipeline that leads to a scientific career at any of the six age marks. It happens at every transition: from middle to high school, from high school to University and from a first degree to graduate school. Students who lose interest in pursuing science and engineering studies and potential careers at a specific educational time point may do so either because they decide that another field interests them more than science or because they decide to opt out of the educational requirements of a scientific career. Either way, this is a problem that needs to be solved in order to ensure the human resources required in science.

\section{Outlook on the future}

The goal of the European Union and its members states must be to have a world-class science community, not only for the better understanding of our world and the laws of nature, but because Europe should also be a place where good ideas and inventions turn naturally into innovation. This requires a long-term research strategy.

We need more strategic and prioritized higher investment in research-both basic research and applied research. The goal is to create excellent research centres and innovative environments to attract entrepreneurs.

The essential condition for this includes higher investments in university education and more $\mathrm{PhD}$ and post-doctoral positions. This can not be done without better edu...Europe should also be a place where good ideas and inventions turn naturally into innovation. cation in science and tehcnology in primary and secondary school to ensure the food chain to higher education in science and technology.

At the same time, the quantity and the quality of $R \& D$ spending in the private sector have to be increased, which requires the appropriate fiscal and regulatory framework- such as a Community patent or a community science curriculum-to be put in place. And last but not least we have to turn "brain drain" into "brain gain" by attracting more non-EU researchers.

This is the way to achieve the Lisbon goal: to become the most competitive and dynamic economy in the world capable of sustainable economic growth with more and better jobs and greater social cohesion. And the EPS must consider how best to play its part in meeting this challenge.

\section{About the auhor}

Anne-Marie Levy is Head of Research Policy at The Science Faculty at University of Copenhagen, Denmark. Before that she worked as an advisor in research and education policy at The Confederation of Danish Industries. She has a master in physics from The University of Copenhagen and is a member of The Executive Committee Board of EPS. 